\title{
LOS INCIDENTES, EXCEPCIONES Y NULIDADES DEL PROCESO PENAL HONDUREÑO
}

\section{THE INCIDENTS, EXCEPTIONS AND ANNULMENTS OF THE HONDURAN CRIMINAL PROCESS}



Enrique Flores Rodríguez

Máster en Derechos Humanos por la

Universidad Autónoma de San Luis Potosí

enrique.flores@umh.edu.hn

Honduras

\section{RESUMEN}

El presente trabajo pretende establecer de forma general, pero clara, la íntima relación que tiene el proceso penal con los derechos fundamentales constitucionalmente establecidos y protegidos por el derecho internacional de los derechos humanos. Estableciendo el alcance y características que tienen los incidentes, las nulidades y excepciones del proceso penal hondureño.

PALABRAS CLAVES: Debido proceso, legalidad, proceso penal, incidentes, nulidades y excepciones.

\section{ABSTRACT \\ This paper seeks to establish in a general but clear manner the intimate relationship that the criminal process has with the fundamental rights constitutionally established and protected by}

international human rights law. It establishes the scope and characteristics of incidents, nullities and exceptions in the Honduran criminal process.

KEYWORDS: Due process, legality, criminal process, incidents, nullities and exceptions.

\section{METODOLOGÍA}

Metodología de la Investigación jurídica: Para el presente trabajo se utilizó la metodología práctica ${ }^{1}$ ,con el fin de facilitar el estudio y razonamiento con el cual en la práctica judicial se ha venido construyendo y tipificando las distintas clases de incidentes, nulidades y excepciones. Ante esto, el método de la doctrina, permite cuadrar de forma ordenada los diversos estamentos que, por sí solos en la legislación son difíciles de distinguir, sin una guía o una estructura doctrinal, para definir, clasificar e identificar los supuestos procesales que acarrea la litis práctica del debido proceso en el ámbito judicial $^{2}$. Esta Metodología de la Investigación jurídica permitió el estudio y análisis de la legislación procesal penal vigente en Honduras, mediante el vivo intercambio entre la doctrina, la jurisprudencia y la ley. Basada en la corriente de investigación jurídico pura -desarrollada por Sánchez Zorrilla sirven como herramientas prácticas para dilucidar dentro de una norma su contenido y estructura, algo indispensable en el trabajo para lograr identificar el grado de nexo entre la norma procesal y el estándar del debido proceso en el derecho internacional de los derechos humanos.

\section{INTRODUCCIÓN}

El proceso penal tiene como fin asegurar la realización de la justicia, en cada uno de los casos sometidos a él, garantizando con ello el acceso adecuado y efectivo para que las partes pueden adentrarse en igualdad de condiciones. Por tanto,

1 La metodología práctica se ocupa de conocer la forma en que resuelven los jueces (o un órgano administrativo) una controversia jurídica. Se preocupa por su razonamiento, por sus criterios de argumentación, por la forma en que son capaces de interpretar las normas en el caso específico resuelto por ellos. De modo tal que se pueda construir de forma ordenada y lógica, un método que servirá para que otros jueces o doctrinarios hagan lo mismo. Este razonamiento resulta atractivo no sólo para la metodología del derecho, pues, en vista de que los jueces tienen que motivar sus sentencias, mediante razonamientos congruentes del veredicto al que llegọ él o ellos (cuando es colegiado) o el jurado (si el sistema los utiliza) en un caso concreto; es comprensible que esta forma de trabajar hayạ ocasionado que la epistemología también le preste atención. Así, Popper utiliza este razonamiento para sostener que las hipótesis científicas (o la decisión final a la que llega el jurado), no pueden ser inferidas por procedimientos inductivos, sino que unicamente pueden justificarse "por medio de otros enunciados - o deducirlos lógicamente de ellos-:

2. Para Sánchez Zorrilla (2011) existen dos preocupaciones con este método. La primera preocupación que tienen es saber qué significa el texto de una norma; es decir, exponernos qué casos resuelve esa norma (o normas), o, en segundo lugar, decirnos cuál es la respuesta adecuada a un problema planteado. En ambos asuntos las investigaciones doctrinales cumplen el rol de manuales 18. Por lo cual, la doctrina actual, casi unánimemente, sostiene que las construcciones dogmáticas tienen que cumplir un fin práctico. 
es preciso para llegar a tal fin, que el mismo se constituya sobre una base de garantías y normas fundamentales, que puedan excluir todas aquellas actividades, vicios o situaciones procesales que pongan en precario la aplicación de la ley o afectar la continuidad del proceso. Para lograr anterior, fue indispensable primero, definir el concepto de forma general, ubicar su posición en la norma procesal y su definición doctrinal; segundo fue necesario dividir el articulado, a modo de clasificar y estructurar, los subtipos de cada de concepto desarrollado por la doctrina y y plasmado dentro de la legislación como causales o consecuencias jurídico-procesales; por último, el tercer punto para estructurar el presente trabajo, era lograr distinguir el alcance de cada figura y su afectación práctica, para entender el agravio que causa a los estándares del debido proceso. Por ello, se inicia dividiendo los incidentes, las nulidades y excepciones, para posteriormente, ubicarlas dentro del proceso penal, conocer su concepto y generalidad, su clasificación, el momento procesal (dentro del proceso ordinario) para su argumentación, su clasificación y su afectación al proceso.

En el proceso de consolidación de limites como garantías frente al poder punitivo del Estado, se reconoce un desarrollo formal, significativo, que permite la aplicación del derecho penal sustantivo, mediante un conjunto de normas que regulan la actividad procesal, derecho penal adjetivo. Es así que, los principios de legalidad, debido proceso, lesividad, humanidad y proporcionalidad, forman la base jurídica, que permiten controlar los actos procesales cuya función es controlar, sanear, permitir, garantizar y prohibir, dependiendo la circunstancia o acto procesal, ajeno al hecho punible, los actos jurídicos que inciden en el desarrollo adecuado de la persecución penal. Surgiendo de esta manera los incidentes, excepciones y nulidades del proceso penal.

\section{DE LOS INCIDENTES, EXCEPCIONES Y NULIDADES EN EL PROCESO PENAL}

\section{Generalidad}

El proceso penal ordinario en Honduras se divide en tres etapas claramente diferentes, regula los actos procesales y las circunstancias por las cuales se puede plantear un incidente o una nulidad. Dicha división y fraccionamiento dentro del sistema procesal, responde al proyecto del código procesal tipo para Iberoamérica, que se adecua doctrinalmente al modelo acusatorio y oral, el cual otorga directamente al fiscal, la investigación de los hechos, es el encargado de preparar y presentar la acusación; para acentuar el carácter acusatorio, dejando clara la división entre los intervinientes, de modo que el Ministerio Publico es el encargado de investigar, quedando a reserva del juez, la tarea de autorizar y tomar decisiones jurisdiccionales, pero no de investigar, ni aportar prueba ${ }^{3}$. Convirtiendo al juez en un verdadero director del proceso. Los Fiscales tienen la responsabilidad de la investigación y la acusación (en caso de proceder), y por ende los jueces la responsabilidad de vigilar y controlar la legalidad de la investigación, además de sus atribuciones judiciales.

Entre tanto, la defensa ejerce un rol de garantía frente al proceso como condición de credibilidad del derecho penal, que tiene el derecho de defensa a la refutación de la acusación. Y se entiende, consiguientemente, el valor de la garantía de tal derecho, constituida por el derecho de defensa del imputado (con el nombramiento de su defensor de confianza o asistencia de la defensa pública).

Con carácter de derecho fundamental y, por ello, universal del derecho de defensa, cuya actuación, justamente porque se trata de un derecho fundamental, no puede ser confiada a las lógicas del mercado como si se tratase de un derecho patrimonial, sino que requiere estar garantizada por la esfera pública. En suma, debe ser asegurada por el Estado, cada vez que el imputado no decida elegir un defensor de confianza (Ferrajoli, 2008).

La división estructural del proceso conlleva la implementación del sistema por audiencias (esquema mixto, porque se mantiene la expresión escrita en los actos postulatorios e impugnativos, en general) sigue representado el programa medular de la reforma de la justicia. Es el único método que asegura la virtualidad y operatividad de los principios cardinales del proceso: inmediación, concentración, celeridad, economía, buena fe, publicidad y desacralización y reverencia de las formas procesales, insta en la oralidad, así como de identidad del juez que asume las pruebas y decide las causas. Ello se complementa con la ampliación y regulación de las facultades del Juez, sobre todo en materia probatoria (siempre en el marco de los hechos alegados y controvertidos por las partes), y su facultad de valorar dicha prueba, conforme con las reglas racionales de la sana crítica (Campos, 2012).

\section{De la etapa preparatoria}

La etapa preparatoria se caracteriza por la recopilación de fuentes de prueba e indicios que permitan develar la existencia o no de un ilícito y, de darse lo primero, identificar a los perpetradores del mismo. De modo de llegar con un mayor grado de convicción a la etapa de juicio oral donde precisamente dichas pruebas e indicios serán actuados y contrastados con los

3 Con su respectiva excepción en juicio con el auto para mejor proveer. 
argumentos del procesado. El inicio del juicio oral depende, precisamente, de un debido «saneamiento procesal».

Mediante este se busca evitar que sean llevados a juzgamiento casos bagatela o insignificantes, y todos aquellos que no han cumplido debidamente con los presupuestos materiales y procesales que la norma exige o, en el peor de los casos, que han sido imputados con inconsistencia o que no han sido suficientemente aparejados de elementos de convicción por parte del Ministerio Público (Trujillo, 2009).

La etapa preparatoria, conformada por la denuncia (si se presenta), la investigación preliminar, requerimiento fiscal, la declaración del imputado y la audiencia inicial (Art. 264 y 286 Código Procesal Penal).

Luego de los actos iniciales del proceso, sea la denuncia, la investigación o la detención en flagrancia, mediante los cuales ingresa formalmente un supuesto hecho delictivo al sistema judicial, comienza la etapa preparatoria, consistente en actos y diligencias, fundamentalmente de investigación, orientados a determinar si existen razones suficientes para presentar la acusación y someter a una persona al proceso penal. El requerimiento fiscal, consiste en establecer que hay elementos para comenzar un proceso en contra de una persona, por realizar una conducta ilícita, por ello se denomina acusación. Por ende, una vez iniciado estos actos dentro del proceso, se activa un engranaje de actos procesales a cargo del Ministerio Público, tendientes a transformar la teoría del caso del Ministerio Público, en la acusación o investigación fiscal dentro de la etapa preparatoria. Ya que, dentro de esta etapa se resuelven situaciones que afectan directamente garantías judiciales, procesales $\mathrm{o}$ bienes y derechos fundamentales, por ejemplo, allanamientos, secuestros, incautaciones, etc.

Durante esta etapa existen básicamente cuatro clases de actos: a) diligencias propias de investigación; b) resoluciones que dirigen la marcha del proceso; c) realización de anticipos jurisdiccionales de prueba; d) resoluciones, decisiones o autorizaciones jurisdiccionales, referidas a actos que puedan afectar garantías procesales o derechos constitucionales. Con relación a este último punto los sujetos procesales pueden oponer excepciones o nulidades, u otra cuestión incidental (Gonzáles, 2002).

\section{DE LAS EXCEPCIONES}

Las excepciones que admite el proceso penal hondureño son el resultado de la configuración y consolidación de límites y garantías frente al control punitivo del Estado, el cual conoce también un desarrollo formal no menos significativo a través de estas. El Código procesal penal en el artículo 46 prevé tres excepciones admisibles:

1. La incompetencia;

2. La falta de acción, cuando no haya debido promoverse o cuando no pueda proseguirse; $y$,

3. La extinción de la acción penal.

El momento procesal para interponer la excepción por incompetencia, es durante la audiencia inicial y podrá hacerlo de forma oral (Art. 48 C.P.P. $)^{4}$.

\section{Falta de acción}

La falta de acción para promover o continuar un proceso penal recae en la legitimidad con la que procede o no una acción penal. Por ejemplo, puede referirse a normas relativas a los sujetos protagonistas de un posible litigio, como ser el órgano jurisdiccional (incompetencia), los legitimados activos o los legitimados pasivos; los cuales pueden verse condicionados por el derecho al ejercicio de la pretensión o de ejercicio en la acción penal. Es así como la Corte Suprema de Justicia de Honduras ha reiterado en distintos casos donde se debate, la representación legal de una sociedad mercantil para comparecer en un proceso penal, que las normas que rigen la representación judicial o extrajudicial de una sociedad mercantil ${ }^{5}$, deben ser consideradas al momento de entender quién puede o no ejercer actos de representación. Uno de los métodos más útiles en orden a la interpretación de las normas y que es aplicable a cualquier rama o sector del ordenamiento jurídico, es el método lógico o sistemático al que alude el artículo 19 párrafo primero del Código Civil, donde establece que “...El contexto de la ley servirá para ilustrar el sentido de cada una de sus partes, de manera que haya entre todas ellas la debida correspondencia y armonía..." (Amparo Penal, AP-164-13, 2013). Teniendo en cuenta que existe un elemento normativo en la representación de una empresa, que

4Para efectos de la admisión de la excepción de incompetencia. Una vẹz firme la sentencia que declara la incompetencia, el órgano jurisdiccional remitirá de oficio los antecedentes al que se considere competente y pondrá a su disposición las correspoṇdientes pruebas o piezas de convicción. Lo anterior, no obstará para que adopte las mẹedidas que considere urgentes y necesarias para la buena marcha del juicio. En caso de existir múltiple y simultánea persecución penal, se actuará de acuerdo con las normas que regulan las cuestiones de competencia

5 Código de Comercio, el acta de constitución, los estatutos, dependiendo el tipo de sociedad. 
remite a la legislación mercantil especializada, cuya omisión, vulnera la garantía del debido proceso, si se acepta la participación de legitimación activa de un representante sin estar autorizado para ello (Amparo Penal 2013, AP-164-13).

\section{Sobre la Extinción de la acción penal}

La acción penal se extingue por prescripción y por extinción de la responsabilidad. Se trata de un conjunto de circunstancias diferentes de carácter natural, legal, político criminal o privado, ajenas al hecho punible, pero que extinguen su posibilidad de persecución y por ende de sanción, ambas constitutivas de la acción penal; sobreviven después de la comisión del delito y anulan la acción (Prado, 2000). Esta división subsiste tanto en la normativa penal de 1983, como en el Código Penal de 2017, encontrando las causales entre los artículos 96 y 97 del primero; y en el Titulo VIII desde el artículo 107 al 116, del segundo; además de contemplar la extinción por el cumplimiento de arreglos en medidas desjudicializadoras.

\section{NULIDADES}

\section{Concepto y generalidades}

Fernando de la Rua (1980) define la nulidad como "la sanción por la cual se declara inválido un acto procesal privándolo de sus efectos, por haber sido cumplido sin observar los requisitos esenciales de la ley" (p.67). Para Sergio Gabriel Torres (2003) nulidad "es la sanción legal, sea expresa o tácita, por la cual se priva de todo efecto jurídico en el proceso a un acto que se cumplió sin observar las formas para el exigidas" (p.31). Teniendo, por ende, un fin mediato que versa sobre el buen orden del proceso; y un inmediato, con los derechos de la sociedad, la víctima y el imputado, con la finalidad de preservar el debido proceso y la inviolabilidad de los derechos fundamentales, es decir, "la nulidad es el guardián de las garantías constitucionales en el proceso penal" (Torres 2003, et al, p. 31).

Las nulidades deben contemplar dos aspectos básicos un interés y un perjuicio. El primero debe entenderse como la actividad procesal desarrollada por conveniencia o necesidad por alguna de las partes con el fin de obtener un provecho a su causa. La segunda recae sobre la limitación y afectación directa o indirectamente, de un derecho de las partes vinculado de forma inmediata al orden armonioso del proceso (por ende, una afectación concreta al debido proceso); y de forma mediata a las garantías de su causa (Torres, 2003). Es decir, que no basta con verificar la existencia de la nulidad, sino también el perjuicio que causa.

En dicho sentido el Código Procesal Penal (CPP, art. 165) establece que las nulidades tienen además un carácter excepcional, produciéndose la nulidad sobre los actos procedimentales cuando expresamente así se establezca $^{6}$. Por reclamación de la parte perjudicada (Art. 167 C.P.P). Tomando en cuenta la formulación del agravio, demostrando mediante el ejercicio de exclusión hipotética que, si no se hubiera admitido o se admitiera, el resultado sería otro (Llobet, 2004) ${ }^{7}$. Siendo obligatorio además establecer el tipo de nulidad y el alcance que tuvo la misma en el proceso.

\section{Clasificación}

Las nulidades pueden ser absolutas y relativas; totales y parciales. Las nulidades absolutas son las que se aplican cuando afecta el orden público o alguna garantía constitucional, en tanto las relativas surgen cuando "el acto afecta un interés particular, rigiéndose por el beneficio de las partes" (Torres, et al, p.58). Dicha división es doctrinal, sin embargo, el código procesal penal rige las mismas en cuanto a características (por ejemplo, en el alcance de nulidades reconoce la nulidad total y parcial) y; han sido reconocidas por la jurisprudencia de Corte Suprema de Justica de Honduras.

Para el Dr. Sergio Gabriel Torres (2003) las absolutas deben tener los siguientes elementos: deben ser declaradas de oficio, pueden declararse en cualquier estado del proceso, pueden plantearse por cualquiera de las partes y, no pueden ser subsanables. En cuanto a las relativas: pueden ser declaradas de oficio, no puede plantearla quien la haya provocado, solo puede

6 Principio de excepcionalidad de la nulidad. La inobservancia de las normas contenidas en este Código, solo producirá la nulidad de los actos procedimentales, cuando así se establezca expresamente, sin perjuicio de la responsabilidad penal, civil o disciplinaria en que hayan podido incurrir los infractores.

7 Para algunos expertos como Javier Llobet el alcance de la nulidad por ejemplo en La admisión equivocada de prueba donde debió considerarse como ilícita, da lugar a la nulidad o ineficacia de la sentencia, cuando la misma descanse en forma esencial en esa prueba, que puede ser reclamada a través del recurso en contra de la sentencia (Vicio de falta de fundamentación de la sentencia). 
exigirla quien tenga interés $y$, son subsanables ${ }^{8}$. Por ejemplo, en dicho sentido el código procesal penal establece que no puede pretender la nulidad la parte que dio lugar a la nulidad y será rechazada cuando solo trate de dilatar el proceso o corregir una deficiencia imputable al reclamante, dejando precluir la oportunidad de subsanarla (C.P.P., art. 167)9.

Dependiendo el alcance de la nulidad estas pueden ser totales o parciales; donde es necesario para que sea declarada una nulidad parcial que el acto sea divisible (Torres, et al, 2003). Por ejemplo, las establecidas en el artículo $166 \mathrm{n}^{\circ} 3$ que señala que "con inobservancia de las disposiciones concernientes a la intervención y participación del imputado en el procedimiento...", como en una declaración, un reconocimiento en rueda o un acta de comiso o secuestro, no pueden ser nulos más que en su integridad misma, donde además es absoluta. Si los motivos de nulidad afectan una parte dentro de un conjunto de disposiciones, se puede nulificar la parte y hacer valer las restantes. Por ejemplo, si en un caso existen varios imputados y el acto declarado nulo solo surte efecto para un imputado. Como en el caso del Amparo Penal AP-199-11 (2012) donde los efectos de la nulidad de oficio, declarada por la corte de apelaciones y ratificada por la Sala de lo Constitucional, cubren únicamente a la parte afectada y no al resto de imputados. En dicha jurisprudencia la Corte además recalcó que, para la Sala de lo Constitucional:

- $\quad[E] s$ claro que la Corte Primera de Apelaciones ha detectado correctamente la existencia de la falta al debido proceso invocada por la parte representada por el amparista; como es una afectación a los principios de contradicción e inmediación, así como al derecho de audiencia, todos los cuales son parte constitutiva y esencial del debido proceso.

\section{Casos en que procede la nulidad}

El código procesal penal establece una serie de supuestos en los cuales un acto procedimental puede ser declarado nulo. Hay que considerar que la nulidad no es un fin en sí misma, sino que tiene como función, preservar las garantías con las que se lleva a cabo el proceso. Por ello es evidente que cualquier acto llevado a cabo violentando las garantías será nulo ${ }^{10}$. Los actos que pueden ser declarados nulos son:

1. Con inobservancia de las disposiciones concernientes al nombramiento, capacidad, jurisdicción o competencia de los órganos jurisdiccionales o de sus integrantes;

2. Con inobservancia de las disposiciones concernientes a la iniciativa de los fiscales y de los acusadores privados, y a su participación en los actos en que su intervención sea necesaria;

3. Con inobservancia de las disposiciones concernientes a la intervención y participación del imputado en el procedimiento, y las relativas a su representación y defensa;

4. Por error sobre sus presupuestos de hecho o bajo violencia física o por efecto de intimidación racional y fundada de un mal inminente y grave, sin perjuicio de las responsabilidades en que podría incurrir la persona causante de la violencia o de la intimidación;

5. Con infracción de las normas esenciales de procedimiento establecidas por este Código, que impida que el acto logre la finalidad que persigue la norma correspondiente;

6. Con infracción de los principios de igualdad entre las partes, de audiencia, contradicción, asistencia y defensa, siempre que hayan producido una

8 Ejemplo de ello lo dispuesto en el art. 170 del C.P.P.

9 Tal como enuncia el Art. 167 en su último párrafo: No podrá pretender la anulación la parte que dio lugar a la causa de nulidad. El órgano jurisdiccional rechazará la pretensión anulatoria, cuando mediante ella se intente tan solo dilatar indebidamente el procedimiento o corregir cualquier deficiencia imputable al reclamante, cuando éste haya dejado precluir la oportunidad de subsanarla.

10 Es indispensable tener en cuenta la doctrina llamada "de la expedición de pesca". Donde existe un supuesto, cuya consecuencia también es la nulidad, en el que no existe acto en sí mismo nulo o prueba obtenida ilegalmente; se trata aquí, de la manera en la que se buscan pruebas y no de la obtención de éstas propiamente dicha. Como ejemplifica el jurista argentino Sergio Torres

"La casa y el lugar de los negocios de una persona no han de ser invadidos por la fuerza y registrados por los curiosos y los suspicaces y aun por un funcionario legal que no tenga interés, salvo que esté provisto de un mandamiento de registro; y la creencia por bien fundada que estuviera, de que un artículo que se busca esté escondido en una casa-habitación, no justifica un registro de aquel lugar, sin mandamiento.. Tales registros han sido declarados ilegales, pese a hechos que incuestionablemente demostrarían su razón probable y una "expedición pesquera" del gobierno en los papeles de una corporación privada, ante la posibilidad de que puedan evidenciar la prueba del delito, no sólo es tan contrario a los principios primordiales de justicia, sino también atentatorio contra esta enmienda." En alusión a los casos Uníted States v. Veeder, 246 v. 675, 1918. Agnello v. United States, 269 v. 20, 1925. Federal Trade Commlssion v. American Tobacco Co., 264 V. 298, 1924. 
efectiva indefensión; $y$,

7. Con violación de los derechos y libertades fundamentales de la persona, consagradas por la Constitución de la República, los Tratados Internacionales de los cuales Honduras forma parte y demás leyes.

No se puede negar que, en la existencia de una nulidad, su causa y su perjuicio pueden ser demostrados. Sin embargo, en algunas ocasiones será sutil y debe ser necesario establecer la particularidad de cada caso, en algunos podrá presentarse incluso prueba para sustentarlo, pero en otros, el vicio podrá no aparecer de forma tangible, por tanto, al tratar de denotar el perjuicio, puede sustentarse en elementos argumentativos. Pero debiendo siempre establecer el vicio y el perjuicio, motivación, frente a las características del acto $^{11}$.

\section{La solicitud de la nulidad y oportunidad procesal}

Como se mencionó en párrafos anteriores, la nulidad puede declararse por parte interesada, como lo establece el art. 167 del CPP o de oficio como versa el art. 168 del CPP. dependiendo de esta y otras características, debiendo entender el tipo y alcance de la nulidad. Dicho esto, la solicitud tiene características particulares dependiendo de quién la plantee. Por ejemplo, el momento procesal.

La nulidad declarada de oficio puede ser invocada únicamente en los casos establecidos en la legislación procesal, donde el órgano jurisdiccional la podrá apreciar por propia iniciativa, siempre y cuando convoque a una audiencia para que las partes comparezcan (C.P.P., art. 168). Teniendo el mismo alcance que las planteadas por parte interesada (C.P.P., art. 169). Serán anulables los actos por reclamación de parte perjudicada, interpuesta en las oportunidades procesales siguientes (C.P.P., art. 167):

1. La nulidad de los actos realizados durante la etapa preparatoria del proceso, en la primera audiencia;

2. La de los realizados durante la audiencia preliminar, antes del auto de apertura de juicio oral;

3. La de los realizados en el auto de apertura del juicio o en el momento de la notificación de este, en fase de preparación del juicio;

4. Las causas de nulidad por hechos sobrevenidos con posterioridad, o por hechos precedentes que no hubieran sido conocidos con anterioridad, en la audiencia anterior al debate, de conformidad con lo previsto por el artículo 316 de este Código; $\mathrm{y}$,

5. Las producidas en el curso del debate o durante la tramitación de un recurso, antes de que (1) uno u otro concluyan.

Sobre el punto primero debe considerarse la primera audiencia como la declaración del imputado o la inicial, dependiendo si el acto que se declarará nulo no dejará en indefensión o subsanará el acto reclamable, por mera omisión. Esta interpretación debe hacerse conforme al art. 8.1 de la Convención Americana sobre Derechos Humanos que establece el derecho a toda persona a ser "oída" en un "plazo razonable" (Ávila, 2015).

El concepto de la razonabilidad del plazo, se sustenta en la base de impedir que las personas procesadas queden en indefensión procesal, no solo en razón de la temporalidad sino, también en razón de la afectación de su derecho de defensa frente al poder punitivo. Por ello en el caso Kawas Fernández vs Honduras (2009) la Corte Interamericana ha establecido que es preciso tomar en cuenta cuatro elementos para determinar la razonabilidad del plazo: a) complejidad del asunto, b) actividad procesal del interesado, c) conducta de las autoridades judiciales, y d) afectación generada en la situación jurídica de la persona involucrada en el proceso (parr.112). Es decir que, el primer momento procesal para presentar la nulidad, depende si el acto recae con afectación a la finalidad de audiencia ${ }^{12} \mathrm{y}$; si el acto que puede considerarse nulo, al no evacuarse en dicha audiencia, subsane el acto viciado por una omisión, provocando un agravio directo en la situación jurídica de la parte afectada.

11 El antepenúltimo párrafo del artículo 167 del C.P.P. establece que "La pretensión anulatoria deberá ser motivada y será resuelta en audiencia dentro de los tres (3) días hábiles siguientes a la fecha de su interposición".

12Por ejemplo, la finalidad de la audiencia de declaración del imputado, que versa sobre un control primario de la detención, la declaración del imputado y la medida cautelar; a diferencia de la inicial donde ya existe un control de la actividad probatoria con la finalidad de aportar material indiciario para resolver sobre la probable realización del hecho que se imputa, sobre su relevancia jurídico penal y la probabilidad de la participación del imputado. Por ende, el momento procesal depende, de donde procesalmente recae el acto que desea ser declarado nulo. 


\section{Alcance de la nulidad}

Según versa el Código Procesal Penal declarada la nulidad, carecerán de valor y efecto alguno no solo el acto viciado, sino también todos los que se hayan realizado con posterioridad, siempre que dependan directamente de aquél (Nulidad Total) $\mathrm{y}$, sean determinados expresamente por el órgano jurisdiccional ${ }^{13}$. Cuando se declare la nulidad parcial de un acto, sus efectos no se extenderán a las partes no afectadas por aquélla. La nulidad de un acto no lleva consigo la de las actuaciones sucesivas que fueren independientes de aquel, ni la de aquellas cuyo contenido habría permanecido, invariable, incluso de no haberse cometido la infracción que dio lugar a la nulidad (CPP, art. 169).

\section{Saneamiento y subsanación de las nulidades}

$\mathrm{Si}$ bien, pueden ser conceptos similares, el Código Procesal Penal los utiliza en dos sentidos relativamente diferentes, entendiéndolos como saneables o convalidables (subsanables). Al hablar de subsanación se refiere a la manifestación expresa o tácita del consentimiento de la parte afectada, posterior a la nulidad. Donde la forma expresa no representa mayor conflicto, pero en la aceptación tácita hay que considerar que "la parte que tenía derecho a alegar la existencia del vicio realiza un comportamiento posterior a él, que evidencia la aceptación de los efectos del acto" (Porras, 1989, p.57). El saneamiento en cambio lo refiere a la forma de enmendar, corregir o rectificar el acto considerado nulo, a modo de aminorar o desaparecer los efectos. Buscando "que la eficacia del acto viciado, para conseguir su fin, requiere la suma de un acto sucesivo que evidencia la producción del efecto físico que el acto buscaba" (Porras, et al, 1989 p.58).

Es así que el Código Procesal Penal establece los supuestos de subsanación del acto viciado tanto expresa o tácitamente ${ }^{14}$, salvo disposición en contrario cuando (CPP, art.170):

Ninguna de las partes haya reclamado oportunamente la declaración de su nulidad, sin perjuicio del poder de iniciativa judicial en los casos expresamente determinados por el Código;
- Las partes hayan aceptado, expresa o tácitamente, los efectos del acto viciado de nulidad;

- No obstante, el vicio, se haya alcanzado la finalidad perseguida mediante el acto viciado; y,

- El órgano jurisdiccional, de oficio o a petición de parte, haya podido eliminar la causa de nulidad.

En tanto versa la normativa procesal "los defectos deberán ser saneados de oficio o a instancia del interesado siempre que sea posible, renovando el acto, rectificando el error o cumpliendo con el acto omitido" (C.P.P., art. 171). Esta renovación o rectificación se cumple mediante la reproducción del acto anulado, a través de la corrección de los defectos del acto; siempre y cuando sea posible por no tratarse de una nulidad absoluta. La excepción de tal acción "salvo los casos expresamente previstos por este Código, no puede retrotraerse el proceso a períodos ya precluidos, bajo pretexto de renovación del acto, de rectificación del error o cumplimiento del acto omitido" (C.P.P., art. 171). Debido a que el saneamiento perdería sentido si la actividad no se justifica o ha perdido importancia para el proceso, estando las partes debidamente protegidas para su defensa; muy a pesar de ser necesario "el acto anulado, no es susceptible de renovación o rectificación, sea por imposibilidad material o jurídica, queda autorizada por la ley la continuidad del proceso sin los actos anulados" (Torres et al., 2003, p.197).

\section{CONCLUSIÓN}

1. Es ineludible que la finalidad del legislador al establecer los supuestos específicos de los incidentes, nulidades y excepciones, en el código procesal penal, en fiel apego al principio de legalidad, debido proceso, entre otros, ha comprendido indispensable para un sistema penal garantista, la correcta conformación e intervención de los actos procesales y situaciones jurídicas que puedan surgir en un proceso penal. Por ende, al momento de plantear cualquier incidente, nulidad o excepción, es obligatorio prever y plantear de forma clara, el alcance, características y afectaciones del acto, para una correcta litigación.

13. Una tendencia a la teoría de los frutos del árbol envenenado, si del acto surgiera un medio de prueba. Como dicta Llobet Rodríguez "Indica que la realización de un acto tendiente a la obtención de prueba de manera ilícita hace que toda la prueba que se derive de la prueba obtenida de manera ilícita sea también ilícita. Lo anterior, aunque con respecto a la prueba derivada se haya sido el procedimiento previsto constitucionalmente".

14 La Jurisprudencia del Amparo AP-579-18 versa en su Considerando n 11 “se tendrá por subsanado el acto viciado cuando ninguna de las partes haya reclamado oportunamente la declaración de nulidad, o cuando las partes hayan aceptado, expresa o tácitamente los efectos del acto viciado de nulidad". 
2. El derecho al debido proceso se refiere al conjunto de requisitos que deben observarse en las instancias procesales a efectos de que las personas estén en condiciones de defender adecuadamente sus derechos ante cualquier acto del Estado, adoptado por cualquier autoridad pública, sea administrativa, legislativa o judicial, que pueda afectarlos.

3. El debido proceso se encuentra, a su vez, íntimamente ligado con la noción de justicia ,que se refleja en: i) un acceso a la justicia no solo formal, sino que reconozca y resuelva los factores de desigualdad real de los justiciables, ii) el desarrollo de un juicio justo, y iii) la resolución de las controversias de forma tal que la decisión adoptada se acerque al mayor nivel de corrección del derecho, es decir que se asegure, en la mayor medida posible, su solución justa, como recalco la Corte Interamericano Caso Torres vs El Salvador (2015).

\section{BIBLIOGRAFÍA}

Amparo Penal CSJ-AP-164-13 (2013). Sistema de

indexación jurisprudencial CSJ de Honduras.

Magistrado Elmer Lizardo Carranza,

http://jurisprudencia.poderjudicial.gob.hn/ConsultaHN/

PDFAmparo.aspx?opcion $=1 \&$ reg $=8057$

Amparo Penal CSJ-AP-199-11 (2012). Sistema de

indexación jurisprudencial CSJ de Honduras.

Magistrado Edwin Francisco Ortez Cruz,

http://jurisprudencia.poderjudicial.gob.hn/ConsultaHN/

VerAmparo.aspx?reg=8868

Amparo Penal CSJ-AP-579-18 (2018). Sistema de

indexación jurisprudencial CSJ de Honduras.

Magistrado José Francisco Ruiz Gaekel.

http://jurisprudencia.poderjudicial.gob.hn/

ConsultaHN/VerAmparo.aspx?reg=3772

Ávila, F.A. (2015). Proceso penal hondureño. (G\&F

Impresiones), 2015, Tomo I 784 p. Tomo II 456

p. ISBN: 978-99926-49-87-9

Campos, S. P. (2012). Alguna Lecciones Aprendidas en la Aplicación del Código Procesal Modelo para Iberoamérica en Uruguay. Derecho \& Sociedad, (38), 297-315.

De la Rúa, F. (1980). Proceso y justicia. Asociados. Buenos Aires. Lerner.

Ferrajoli, L. (2008). La desigualdad ante la justicia penal y la garantía de la defensa pública. Ministerio público de la defensa, asociación interamericana de defensorías públicas. Defensa pública: garantía de acceso a la justicia. Editorial La Ley.

Macchi, J. I. G. (2002). La Reforma del Proceso Penal. Revistas de Ciências Jurídicas e Sociais da UNIPAR, 5(2).

Porras, Isabel Porras. "Las nulidades en el proceso penal costarricense." Revista de Ciencias Jurídicas 63 (1989).

Príncipe Trujillo, H. (2009). La etapa intermedia en el proceso penal peruano: su importancia en el Código Procesal Penal de 2004 y su novedosa incidencia en el Código de Procedimientos Penales (CdePP).

Salazar, J. J. U., \& Rodríguez, J. L. (2004). Actividad procesal defectuosa y proceso penal. Ed. Jurídica Continental.

Saldarriaga, Víctor Prado. "Causales de extinción de la acción penal y de la ejecución de la pena.” Derecho PUCP 53 (2000).

Torres, S. G. (2003). Nulidades en el proceso penal. AdHoc. 2 edición.

Zorrilla, M. S. (2011). La metodología en la investigación jurídica: características peculiares y pautas generales para investigar en el derecho. Revista telemática de filosofía del derecho (RTFD), (14), 317-358. 